\title{
Effect of Hypoxia on Ventilatory Control during Exercise in Children and Adults
}

\author{
CHAIM SPRINGER, THOMAS J. BARSTOW, AND DAN M. COOPER
}

Division of Respiratory and Critical Care, Department of Pediatrics, Division of Respiratory and Critical Care Physiology and Medicine, Department of Medicine, Harbor-UCLA Medical Center, Torrance, California 90509

\begin{abstract}
Little is known about maturation of peripheral chemoreceptor tone (PCT) during growth. We recently demonstrated that the increase in PCT was $49 \%$ greater during hypoxic $\left(15 \% \mathrm{O}_{2}\right)$ exercise in children compared to adults. As the PCT is a major determinant of ventilatory $\left(\dot{V}_{E}\right)$ response at the onset of exercise (measured by the time constant $\tau$ ), we hypothesized that hypoxia would affect $\tau \dot{\mathbf{V}}_{\mathrm{E}}$ (and $\tau \dot{\mathbf{V}}_{\mathrm{CO}_{2}}$ ) to a greater extent in children. Nine healthy children (6-10 y old) and nine healthy adults (18$40 \mathrm{y}$ old) performed multiple transitions from rest to constant work rate on the cycle ergometer. Studies were done breathing $21 \% \mathrm{O}_{2}$ and $15 \% \mathrm{O}_{2}$. Hypoxic breathing quickened the $\dot{V}_{E}$ responses in all of the adults and children, but the magnitude of the hypoxic effect did not differ between the two groups (in children, $\tau \dot{\mathrm{V}}_{\mathrm{E}}$ was $50.9 \pm 9.9 \mathrm{~s}$ during $21 \% \mathrm{O}_{2}$ breathing and $32.6 \pm 6.9 \mathrm{~s}$ during hypoxia; in adults, $\tau \dot{\mathrm{V}}_{\mathrm{E}}$ was $69.4 \pm 17.6 \mathrm{~s}$, which fell to $50.9 \pm 18.4 \mathrm{~s}$ during hypoxia). The hypothesized greater ventilatory response to hypoxia in children compared to adults during exercise was not observed. During $21 \% \mathrm{O}_{2}$ breathing, the data demonstrated that children stored relatively less $\mathrm{CO}_{2}$ (by $49 \%$ ) than did adults in the transition between rest and exercise, possibly explaining the faster ventilatory kinetics. We speculate that there must be additional respiratory control differences between adults and children such that for a given increase in PCT-induced by hypoxia, the $\dot{V}_{E}$ response at the onset of exercise is less in children than in adults. (Pediatr Res 25:285-290, 1989)
\end{abstract}

Abbreviations

$\dot{\mathrm{V}}_{\mathrm{E}}$, minute ventilation

$\dot{\mathrm{V}}_{\mathrm{CO}_{2}}, \mathrm{CO}_{2}$ output

$\dot{\mathrm{V}}_{\mathrm{O}_{2}}, \mathrm{O}_{2}$ uptake

AT, anaerobic threshold

PCT, peripheral chemoreceptor tone

Much is known about the peripheral chemoreceptors (carotid bodies) as the important mediators of the hypoxic drive to ventilation in both babies and adults (1-3). But little is known about their function and possible maturation during the growth process of normal children. Recently, we examined the PCT in a group of children and adults by measuring the fall in $\dot{V}_{\mathrm{E}}$ during a hyperoxic switch [i.e. the sudden imposition of $80 \%$ oxygen that is known to eliminate carotid body input to ventilation (4,

Received June 6, 1988; accepted November 3, 1988.

Correspondence Dan M. Cooper, M.D. A-17 Annex, Harbor-UCLA Medical Center, 1000 West Carson Street, Torrance, CA 90509.

CS is supported by a fellowship from the Joseph Drown Foundation. This work was supported by NIH Grant HL11907 and a grant from the California Lung Association.
5)] during steady-state exercise (6). The PCT was then defined as the maximum percentage of reduction in ventilation seen during the hyperoxic switch. PCT was similar in children and adults during air-breathing exercise $(27.9 \pm 10.7 \% 1 \mathrm{SD}$ reduction in children and $23.3 \pm 6.3 \%$ in adults, not statistically significant), but during $15 \% \mathrm{O}_{2}$ breathing, the peripheral chemoreceptor contribution to ventilation was much greater in the children $(57.6 \pm 3.6 \%$ in children and $38.9 \pm 5.5 \%$ in adults, $p$ $<0.0001)$. We concluded that peripheral chemoreceptor function matures during growth and is characterized by decreasing sensitivity to hypoxia.

Our studies on carotid body tone were made during steadystate exercise. But the ability of the organism to maintain homeostasis is better assessed by focusing on the transition between rest and exercise when sudden and large increases in cellular $\mathrm{CO}_{2}$ output and $\mathrm{O}_{2}$ consumption occur. The carotid bodies are known to play an important role in the ventilatory response that occurs in the transition from rest to exercise $(1,3,7)$. The responses are slow in carotid body resected patients (3) and, as noted above, in healthy subjects who breathe high concentrations of $\mathrm{O}_{2}$. Conversely, breathing hypoxic gas mixtures stimulates the carotid bodies and quickens the ventilatory responses to exercise (1). We wondered whether an increase in peripheral chemoreceptor tone induced by breathing hypoxic air would have the same effect on ventilatory responses to exercise in the child as in the adult.

To examine the linkage of peripheral chemoreceptor tone and the ventilatory response, we measured the gas exchange responses to the sudden onset of exercise in a group of children and adults using cycle ergometry and breath by breath data acquisition. The ventilatory response to the transition between rest and exercise has been characterized in both adults and children to consist of three phases $(7,8)$, where phase 1 is the rapid increase in $\dot{V}_{\mathrm{E}}$, $\dot{\mathrm{V}}_{\mathrm{CO}_{2}}$ and $\dot{\mathrm{V}}_{\mathrm{O}_{2}}$ in the first $15-20$ s of exercise; phase 2 is the exponential increase, and phase 3 is the final steady-state response. The phase 2 response is apparently most influenced by the carotid bodies (3) with phase 1 reflecting a sudden increase in cardiac output (9). In both the adults and children, the responses were measured under air-breathing conditions and compared to hypoxic gas breathing, which stimulated the peripheral chemoreceptors.

\section{MATERIALS AND METHODS}

Population. Nine healthy children (five boys and four girls, aged $6-10 \mathrm{y}$, mean age $8.2 \pm 1.4 \mathrm{y}$ ) and nine healthy adults (five males and four females, aged $18-40 \mathrm{y}$, mean age $28.2 \pm 6.9 \mathrm{y}$ ) comprised the study population (Table 1). All were volunteers, had no chronic diseases, and did not smoke or use medications. The study was approved by the Human Subjects Committee of Harbor-UCLA Medical Center. Informed consent was obtained from each subject and guardian when appropriate.

Protocol. 1) Progressive exercise tests: Each subject performed a ramp-type progressive exercise test on a cycle ergometer (10) 
Table 1. Subjects data

\begin{tabular}{|c|c|c|c|c|c|c|c|c|c|c|c|}
\hline \multicolumn{6}{|c|}{ Children } & \multicolumn{6}{|c|}{ Adults } \\
\hline No. & Sex & Age $(y)$ & Wt $(\mathrm{kg})$ & $\mathrm{Ht}(\mathrm{cm})$ & $\begin{array}{c}W^{*} \\
(w)\end{array}$ & No. & Sex & Age $(y)$ & $\mathrm{Wt}(\mathrm{kg})$ & $\mathrm{Ht}(\mathrm{cm})$ & $\begin{array}{l}\text { WR } \\
\text { (W) }\end{array}$ \\
\hline 1 & $\mathrm{~F}$ & 9.1 & 26.4 & 126 & 15 & 1 & $\mathrm{~F}$ & 18.0 & 63.2 & 166 & 29 \\
\hline 2 & M & 6.0 & 20.0 & 113 & 15 & 2 & $\mathrm{M}$ & 26.3 & 70.1 & 180 & 40 \\
\hline 3 & M & 7.5 & 27.0 & 127 & 20 & 3 & $F$ & 25.0 & 58.6 & 161 & 30 \\
\hline 4 & $\mathrm{~F}$ & 8.1 & 28.1 & 145 & 14 & 4 & $F$ & 26.2 & 64.3 & 168 & 40 \\
\hline 5 & $\mathrm{M}$ & 7.2 & 22.7 & 127 & 15 & 5 & M & 40.0 & 65.2 & 170 & 45 \\
\hline 6 & $\mathrm{~F}$ & 9.2 & 23.2 & 132 & 15 & 6 & $M$ & 34.2 & 66.5 & 173 & 80 \\
\hline 7 & $\mathrm{~F}$ & 10.0 & 38.6 & 150 & 22 & 7 & $\mathrm{M}$ & 34.3 & 50.3 & 160 & 35 \\
\hline 8 & $\mathrm{M}$ & 6.9 & 28.1 & 124 & 14 & 8 & $\mathrm{M}$ & 21.4 & 62.2 & 168 & 60 \\
\hline 9 & $\mathrm{M}$ & 10.0 & 49.0 & 151 & 30 & 9 & $\mathrm{M}$ & 28.5 & 75.3 & 175 & 55 \\
\hline Mean & & 8.2 & 29.2 & 133 & 18 & Mean & & 28.2 & 64.0 & 169 & 46 \\
\hline $\mathrm{SD}$ & & 1.4 & 9.1 & 13 & 5 & $\mathrm{SD}$ & & 6.9 & 7.0 & 6 & 16 \\
\hline
\end{tabular}

*WR, work rate.

breathing $15 \% \mathrm{O}_{2}$. This test was used to estimate the $\wedge^{\prime} \mathrm{T}$ during 15\% (), breathing. 2) Constant work rate excrcise tests: Pach subject performed live rest to constant work rate exercise tests, during air-breathing and during $15 \% \mathrm{O}_{2}$ breathing. The subject was signaled to begin exercise by a green light that was activated at end expiration. The ergometer wheel was motorized and maintained at a rate of $60 \mathrm{rpm}$ until the start of exercise to minimize the energy expenditure needed to overeome the flywheel inertia. The work rate used for the constant exercise tests was $75 \%$ of the hypoxic $\wedge \mathrm{T}$ (Table 1). This work rate was chosen to ensure that the tests performed during both air breathing and hypoxic gas breathing would be below the subject's AT. As children and adults have widely different exercise capabilities, the work rate chosen was normalized in each subject to a specific, physiologically based, work intensity. By choosing work ranges below the $\Lambda T$, possible confounding effects of lactic acidosis on ventilation were avoided in both the adults and children. Steadystate exercise continued for $10 \mathrm{~min}$, followed by a period of rest long cnough (approximately $10 \mathrm{~min})$ to allow $\dot{\mathrm{V}}_{\mathrm{l},}, \dot{\mathrm{V}}_{\mathrm{O}_{2}}, \dot{\mathrm{V}}_{\left(\mathrm{O}_{2}\right.}$, and heart rate to return to the preexercise levels. The peripheral chemoreceptor contribution to the ventilatory drive during steady-state exercise, both under air-breathing and hypoxic gasbreathing conditions in the same subjects has been reported by measuring the fall in $\dot{\mathrm{V}}_{1 \text { : }}$ during the imposition of $80 \% \mathrm{O}_{2}$ for 10 breaths, performed after 6 min of exercise (6).

Measurement of ventilation, gas exchange, and heart-rate. Ventilation and gas exchange were measured breath by breath. This allows a precise assessment of the kinetic responses of the ventilatory system. The subjects breathed through a mouthpiece connected to a turbine flowmeter and a low resistance 2-way valve for continuous measurement of inspired and expired vol. The apparatus dead space was $140 \mathrm{~mL}$ for the children and 170 $\mathrm{mL}$, for the adults. $\mathrm{CO}_{2}$ and $\mathrm{O}_{2}$ concentrations were measured by a mass spectrometer that sampled continuously from the mouthpiece at $1 \mathrm{ml} / \mathrm{s}$. $\dot{\mathrm{V}}_{\mathrm{l}}$ (BTPS), $\dot{\mathrm{V}}_{\mathrm{O}_{2}}(\mathrm{STPD}), \dot{\mathrm{V}}_{\left(\mathrm{C}_{2}\right.}(\mathrm{STPD})$, end tidal pressure for $\mathrm{O}_{2}\left(\mathrm{P}_{1: \mathrm{T}_{0}}\right)$ and for $\mathrm{CO}_{2}\left(\mathrm{P}_{\mathrm{Er}}\right)$ were computed online, breath by breath, as previously described (11). Heart rate was measured beat by beat by a standard lead I ECC using three electrodes placed on the chest. The data from each test were stored on digital tape for further analysis.

Data analysis: The $\Lambda \mathrm{T}$ was measured noninvasively from the gas exchange data obtained during the progressive exercise. AT was delined as the $\dot{V}_{O_{2}}$, at which the ventilatory equivalent for $\mathrm{O}_{2}$ $\left(\dot{\mathrm{V}}_{1:} / \dot{\mathrm{V}}_{0}\right)$ and $\mathrm{P}_{1: r_{1,}}$ increase without an increase in the ventilatory equivalent for ()$_{2}\left(\dot{\mathrm{V}}_{\mathrm{r}} / \dot{\mathrm{V}}_{(0)}\right)$ and $\mathrm{P}_{\mathrm{F} T \mathrm{~T}, \mathrm{H}}(10,12,13)$.

The results of each rest to exercise transition for each subject were time aligned and averaged to obtain a second by second response. $\dot{V}_{1}$ and $\dot{V}_{(c)_{2}}$ phase 2 kinetics (beginning approximately

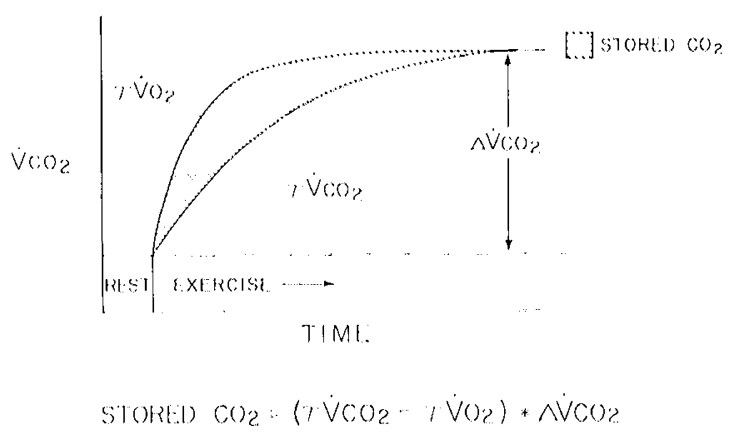

lig. 1. (hanges in tissuc $\mathrm{CO}_{2}$ stores with exercise. Stored $\mathrm{CO}_{2}$ was calculated using the equation shown. $\Delta \dot{V}_{\left(C_{2}\right.}$ is the increase in $\dot{V}_{\left(O_{2}\right.}$, from rest to stcady-state excreise, and $\tau \dot{\mathrm{V}}_{\left({ }_{(}\right)}$, and $r \dot{V}_{()_{2}}$ are the time constants for $\dot{V}_{(0)}$, and $\dot{V}_{()}$.

15-20 s after the start of exercise) were analyzed by fitting the data to a first order exponential model $(14,15)$. The time constant $(\tau)$ of the response was determined from the equation:

$$
\dot{\mathrm{V}}(\mathrm{t})=\dot{\mathrm{V}}(\mathrm{ss}) \cdot\left(\mathrm{I}-\mathrm{c}^{-\left[\left(1-\mathrm{T}_{\mathrm{i}}\right) / \mathrm{r}\right]}\right)
$$

where $\dot{V}(1)$ is the increase in $\dot{V}_{1:}, \dot{V}_{\left({ }^{\prime}\right)_{2}}$, or $\dot{V}_{\mathrm{O}_{2}}$ above the previous control values at any given time $(\mathrm{t}) ; \dot{V}(s s)$ is the difference between rest and steady-state exercise $\dot{V} ; \tau$ is the time to reach $6.3 \%$ of $\dot{V}(s s)$; and $T_{1}$ is the time delay.

Assessment of tissue $\mathrm{C}^{\prime} \mathrm{O}_{2}$ stores. To assess the change in tissue $\mathrm{CO}_{2}$ stores (using gas exchange data) during the transition from rest to exercise, one must estimate the difference between $\mathrm{CO}_{2}$ produced at the muscle and $\mathrm{CO}_{2}$ measured at the mouth. The difference between these values represent stored tissue $\mathrm{CO}_{2}(16)$. We assumed that $\mathrm{CO}_{2}$ production at the muscle followed the same time course as muscle $\mathrm{O}_{2}$ extraction from the blood, thus any difference between $V_{O}$, kinetics and $V_{(}()_{2}$, kinctics at the mouth was attributed to a change in tissue $\mathrm{CO}_{2}$ stores (17). Finally, we made the assumption that any changes in exercise respiratory quotient occurred immediately after the onset of exercise (i.e. as a square wave). In fact, the pattern of respiratory quotient change has been shown to have little effect on the calculation of $\mathrm{CO}$, stores for rest to exercise transitions (16). The estimated changes in stored tissue $\mathrm{CO}_{2}$ were thus calculated as follows (sec Fig. 1):

$$
\Delta \mathrm{CO}_{2}(\text { stores })=\left(\tau \dot{\mathrm{V}}_{\left(\mathrm{CO}_{2}\right.}-\tau \dot{\mathrm{V}}_{\mathrm{O}_{2}}\right) \cdot \Delta \dot{\mathrm{V}}_{\left(\mathrm{C}_{2}\right)_{2}}
$$

where $\tau \dot{V}_{(O)}$, and $\tau \dot{V}_{0}$, were calculated from an exponential fit to the gas exchange data, starting at the onset of exercise, and where $\Delta \dot{V}_{(}^{(}()$, is the difference between rest and steady-state exercise $\dot{V}_{\left({ }^{\prime}()_{2}\right.}$. To compare changes in tissue $\mathrm{CO}_{2}$ stores between children 
and adults, we normalized the increase in $\dot{\mathrm{V}}_{\mathrm{CO}_{2}}$ during exercise in the two groups to body wt:

$$
\Delta_{\mathrm{CO}_{2}} \text { (stores) } \cdot \mathrm{kg}^{-1}=\left(\tau \dot{\mathrm{V}}_{\mathrm{CO}_{2}}-\tau \dot{\mathrm{V}}_{\mathrm{O}_{2}}\right) \cdot \Delta \dot{\mathrm{V}}_{\mathrm{CO}_{2}} \cdot \mathrm{kg}^{-1} \text {. }
$$

Thus, for the same increase in $\dot{\mathrm{V}}_{\mathrm{CO}_{2}} \cdot \mathrm{kg}^{-1}$ in both children and adults, the increase in tissue $\mathrm{CO}_{2}$ stores can be estimated simply by the difference between $\tau \dot{\mathrm{V}}_{\mathrm{CO}_{2}}$ and $\tau \dot{\mathrm{V}}_{\mathrm{O}_{2}}$.

Statistical analysis. Unpaired $t$ tests were used to compare the results between the same variables in children and adults. Paired $t$ tests were used to compare the results of different conditions in the same group. Differences were considered significant at $p<$ 0.05 . Values are expressed as mean $\pm 1 \mathrm{SD}$.

\section{RESULTS}

Hypoxic gas breathing resulted in a significant decrease in

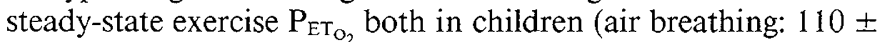
$3 \mathrm{~mm} \mathrm{Hg}, 15 \% \mathrm{O}_{2}$ breathing: $\left.70 \pm 3 \mathrm{~mm} \mathrm{Hg} p<0.0001\right)$ and in adults $(106 \pm 4 \mathrm{~mm} \mathrm{Hg}$ and $67 \pm 3 \mathrm{~mm} \mathrm{Hg}$, respectively, $p$

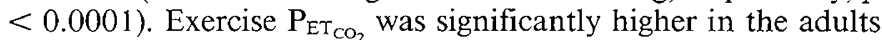
compared to the children both during air breathing (adults: 44 $\pm 4 \mathrm{~mm} \mathrm{Hg}$; children $41 \pm 1 \mathrm{~mm} \mathrm{Hg}, p<0.05$ ) [similar to our previous study (13)] and also during hypoxic gas breathing (adults: $42 \pm 3 \mathrm{~mm} \mathrm{Hg}$; children: $39 \pm 2 \mathrm{~mm} \mathrm{Hg}, p<0.05$ ).

The averaged, time-aligned, breath by breath $\dot{V}_{E}$ responses during air and hypoxic gas breathing in the children and the adults are shown in Figure 2. The best fit exponential for the responses are also shown for each group.
Phase 1 responses. Phase 1 response of $\dot{V}_{E}$ to exercise (the $\dot{V}_{E}$ at $20 \mathrm{~s}$ expressed as the percentage of change from rest to steadystate exercise) decreased significantly during hypoxia in both the children and the adults (Fig. 3). In children, the mean phase 1 $\dot{\mathrm{V}}_{\mathrm{E}}$ decreased from $36.2 \pm 6.6 \%$ during air breathing to $25.5 \pm$ $2.6 \%$ during hypoxic gas breathing, $p<0.0005$. In adults, the mean phase $1 \dot{V}_{E}$ decreased from $42.2 \pm 10.7 \%$ to $32.3 \pm 8.0$, respectively, $p<0.0005$. The absolute value of the phase 1 changes paralleled those of the relative changes. In children, the mean phase $1 \dot{V}_{E}$ decreased from $3.11 \cdot \mathrm{min}^{-1}$ in room air to 2.4

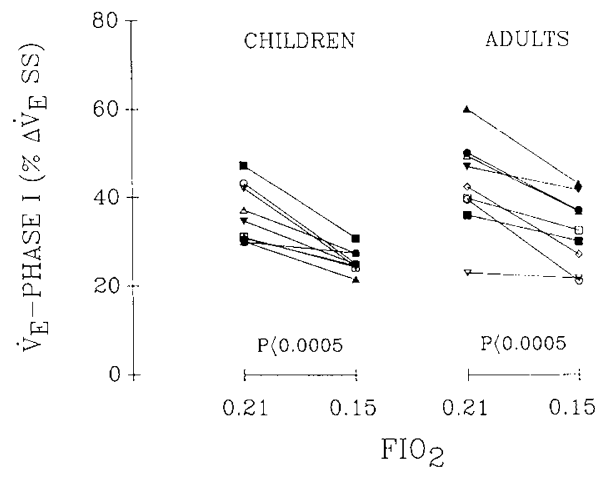

Fig. 3. Effect of hypoxia on $\dot{V}_{E}$, phase 1 in children and adults. $\dot{V}_{E}$ is expressed as the percentage of change from rest to steady-state exercise. Hypoxia resulted in a significant decrease in $\dot{\mathrm{V}}_{\mathrm{E}}$ in both the children and the adults.

\section{CHILDREN}
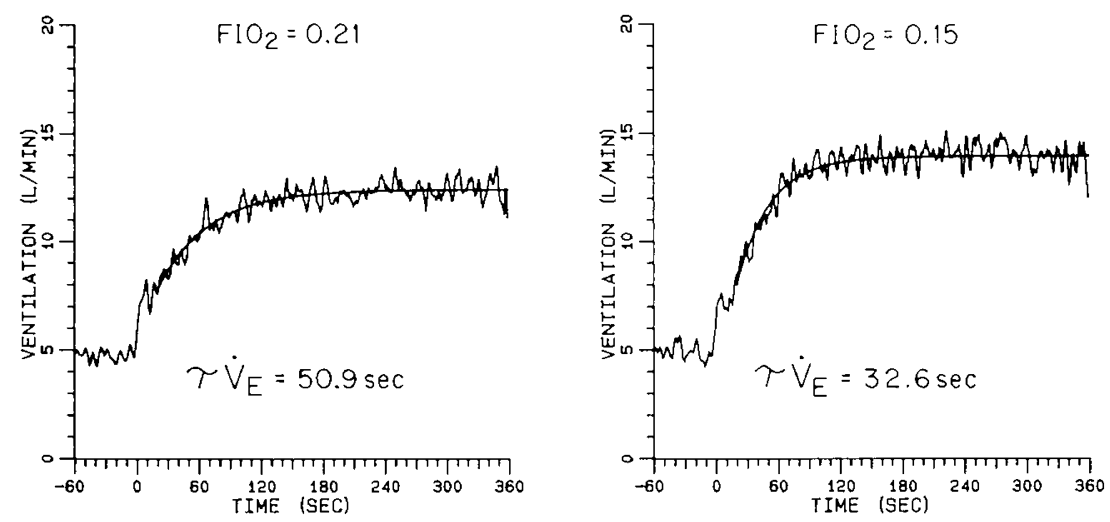

\section{ADULTS}
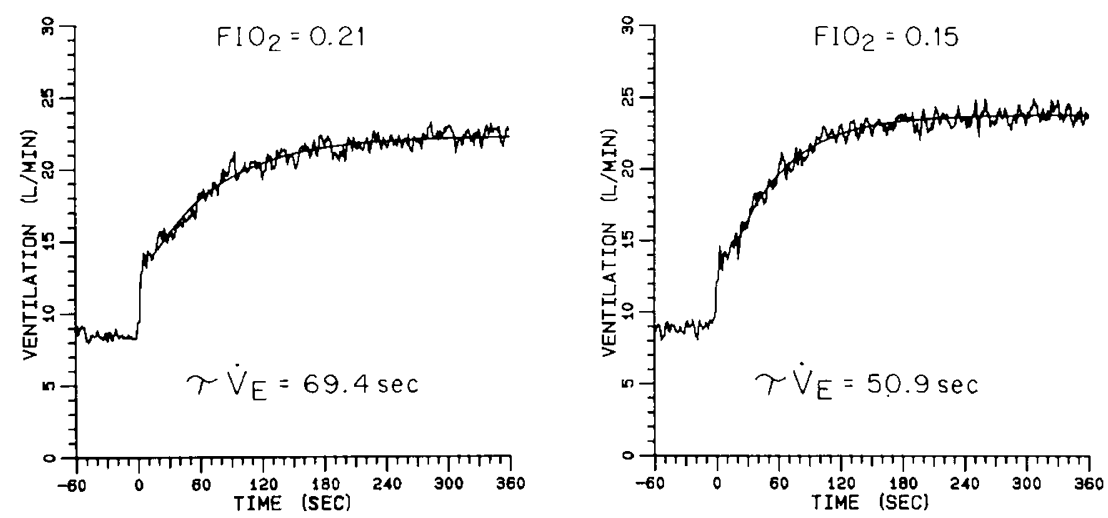

Fig. 2. Averaged time-aligned breath by breath $\dot{V}_{E}$ responses to exercise in children and adults during air-breathing (left) and hypoxic gasbreathing (right). Hypoxia led to faster $\dot{\mathrm{V}}_{\mathrm{E}}$ responses in both the children and the adults. 
$1 \cdot \min ^{-1}$ during hypoxia $(p<0.05)$ and in adults, the decrease was from $6.01 \cdot \mathrm{min}^{-1}$ to $4.61 \cdot \mathrm{min}^{-1}(p<0.05)$.

Phase 2 kinetics. Children compared to adults had significantly shorter $\tau \dot{\mathrm{V}}_{\mathrm{E}}$ and $\tau \dot{\mathrm{V}}_{\mathrm{CO}_{2}}$ (Fig. 4) during air breathing. These results are similar to our previous findings in a different group of healthy subjects (8). In response to hypoxia, there was a significant reduction in $\tau \dot{\mathrm{V}}_{\mathrm{E}}$ and in $\tau \dot{\mathrm{V}}_{\mathrm{CO}_{2}}$ (Fig. 4) in both groups; this occurred in all subjects. In children, mean $\tau \dot{\mathrm{V}}_{\mathrm{E}}$ decreased from $50.9 \pm 9.9 \mathrm{~s}$ to $32.6 \pm 6.9 \mathrm{~s}, p<0.001$, and mean $\tau \dot{\mathrm{V}}_{\mathrm{CO}_{2}}$ decreased from $43.9 \pm 11.0 \mathrm{~s}$ to $33.4 \pm 6.8 \mathrm{~s}, p<0.005$. In the adults, mean $\tau \dot{\mathrm{V}}_{\mathrm{E}}$ decreased from $69.4 \pm 17.6 \mathrm{~s}$ to $50.9 \pm 18.4 \mathrm{~s}, p<$ 0.005 , and mean $\tau \dot{\mathrm{V}}_{\mathrm{CO}_{2}}$ decreased from $59.6 \pm 16.2 \mathrm{~s}$ to $47.7 \pm$ $15.2 \mathrm{~s}, p<0.001$. The mean decrease $(\Delta)$ in $\tau \dot{\mathrm{V}}_{\mathrm{E}}$ and $\tau \dot{\mathrm{V}}_{\mathrm{CO}_{2}}$ induced by hypoxia was not significantly different between children and adults both in absolute (s) or relative (percentage
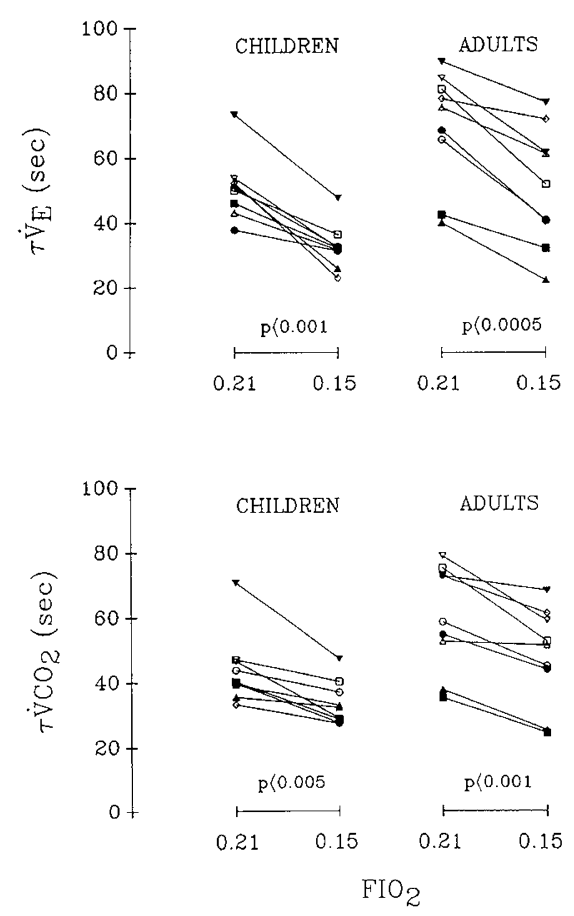

Fig. 4. Effect of hypoxia on $\dot{\mathrm{V}}_{\mathrm{E}}$ and $\dot{\mathrm{V}}_{\mathrm{CO}_{2}}$ responses to exercise in children and adults. Children had significantly shorter time constants both during air-breathing $(p<0.05)$ and hypoxic gas-breathing $(p<$ 0.05 ) studies. In both groups, hypoxia resulted in a significant decrease in $\tau \dot{\mathrm{V}}_{\mathrm{E}}$ and $\tau \dot{\mathrm{V}}_{\mathrm{CO}_{2}}$. decrease) terms. The mean $\Delta \tau \dot{\mathrm{V}}_{\mathrm{E}}$ was $18.3 \pm 7.7 \mathrm{~s}$ in children $(36 \%)$ and $18.5 \pm 8.1 \mathrm{~s}$ in adults $(27 \%)$; mean $\Delta \tau \dot{\mathrm{V}}_{\mathrm{CO}_{2}}$ was 10.5 $\pm 6.5 \mathrm{~s}$ in children $(24 \%)$ and $12.0 \pm 6.6 \mathrm{~s}$ in adults $(20 \%)$.

The estimated increase in tissue $\mathrm{CO}_{2}$ stores/ $\mathrm{kg}$ during sub-AT exercise for a given increase in $\dot{\mathrm{V}}_{\mathrm{CO}_{2}}$ of $1 \mathrm{~mL} \cdot \mathrm{min}^{-1} \cdot \mathrm{kg}^{-1}$ was significantly smaller in children as compared to adults $[0.18 \pm$ $0.07 \mathrm{ml} \mathrm{CO} 2 \cdot \mathrm{kg}^{-1}$ in children and $0.36 \pm 0.13 \mathrm{ml} \mathrm{CO} \cdot \mathrm{kg}^{-1}$ in adults, $p<0.05$ (Table 2$)$ ].

Heart rate. Hypoxia significantly increased heart rate at rest and during exercise in the adults and children. In air-breathing exercise in adults, heart rate increased from a mean of 85 beats/ min to 108 beats/min (mean increase, $28 \pm 12 \%$ ), and in children, heart rate increased from 103 to 135 beats/min (mean increase, $32 \pm 5 \%$ ). With hypoxic gas breathing, heart rate increased in adults from 89 to 114 beats/min (mean increase, 29 $\pm 9 \%$ ), and in children heart rate increased from 110 to 144 beats/min (mean increase, $32 \pm 9 \%$ ). There were no significant differences among the percentage rest to exercise increases in heart rate in children compared to adults.

\section{DISCUSSION}

The results of the present investigation demonstrate that the coupling of PCT assessed during steady-state exercise and ventilatory responses at the onset of exercise is different in children than in adults. During normoxia, young children had significantly faster $\dot{V}_{\mathrm{E}}$ and $\dot{\mathrm{V}}_{\mathrm{CO}_{2}}$ responses to exercise than do teenagers and adults [confirming the findings of our previous study in a different group of normal subjects (8)], despite the fact that PCT was the same in the two groups (Fig. 5). The $\dot{\mathrm{V}}_{\mathrm{E}}$ and $\dot{\mathrm{V}}_{\mathrm{CO}_{2}}$ responses to the onset of exercise became significantly faster in both the children and the adults under hypoxic conditions (Fig. 4), but the magnitude of the change was the same in both groups. This was surprising as the peripheral chemoreceptor contribution to ventilatory drive during hypoxia was much greater in the children (Fig. 5). In summary, the greater carotid body tone during hypoxia in children compared to adults was not paralleled by an increase of the same magnitude in the $\dot{V}_{E}$ response at the onset of exercise.

Cardiac output increases suddenly at the onset of exercise, primarily by an increase in the stroke vol. When the change in stroke vol is limited by increasing resting stroke vol (as occurs when exercise is performed in the supine position), the accompanying ventilatory response is smaller as well (18). The apparent dependence of the early ventilatory response on cardiac output has been named cardiodynamic hyperpnea (9). This effect is limited to phase 1 , the first $20 \mathrm{~s}$ of exercise, and does not appear to influence the subsequent phase 2 response. Interestingly, we

Table 2. $\tau \dot{V}_{\mathrm{CO}_{2}}$ and $\tau \dot{V}_{\mathrm{O}_{2}}$ during air breathing used for calculation of $\mathrm{CO}_{2}$ stores*

\begin{tabular}{|c|c|c|c|c|c|c|c|c|c|}
\hline \multicolumn{5}{|c|}{ Children } & \multicolumn{5}{|c|}{ Adults } \\
\hline No. & $\begin{array}{c}\tau \dot{\mathrm{V}}_{\mathrm{O}_{2}} \\
\text { (s) }\end{array}$ & $\begin{array}{c}\tau \dot{\mathrm{V}}_{\mathrm{CO}_{2}} \\
(\mathrm{~s})\end{array}$ & $\begin{array}{l}\Delta \tau \\
(\mathrm{s})\end{array}$ & $\begin{array}{c}\Delta \dot{\mathrm{V}}_{\mathrm{CO}_{2} \dagger} \dagger \\
1 . \\
\min ^{-1}\end{array}$ & No. & $\begin{array}{c}\tau \dot{\mathrm{V}}_{\mathrm{O}_{2}} \\
\text { (s) }\end{array}$ & $\begin{array}{c}\tau \dot{\mathrm{V}}_{\mathrm{CO}_{2}} \\
(\mathrm{~s})\end{array}$ & $\begin{array}{l}\Delta \tau \\
(\mathrm{s})\end{array}$ & $\begin{array}{l}\Delta \dot{\mathrm{V}}_{\mathrm{CO}_{2}}^{\dagger} \\
1 \cdot \mathrm{min}^{-1}\end{array}$ \\
\hline 1 & 33.5 & 42.8 & 9.3 & 0.40 & 1 & 31.8 & 49.5 & 17.7 & 0.46 \\
\hline 2 & 27.9 & 38.0 & 10.1 & 0.40 & 2 & 33.9 & 53.7 & 19.8 & 0.57 \\
\hline 3 & 28.0 & 41.2 & 13.2 & 0.38 & 3 & 24.0 & 55.2 & 31.2 & 0.51 \\
\hline 4 & 27.4 & 37.0 & 9.6 & 0.32 & 4 & 27.1 & 42.1 & 15.0 & 0.54 \\
\hline 5 & 26.4 & 40.4 & 14.0 & 0.39 & 5 & 39.1 & 60.5 & 21.4 & 0.75 \\
\hline 6 & 27.8 & 40.8 & 13.0 & 0.40 & 6 & 14.8 & 27.7 & 12.9 & 0.84 \\
\hline 7 & 31.0 & 50.0 & 19.0 & 0.44 & 7 & 43.7 & 80.1 & 36.4 & 0.68 \\
\hline 8 & 19.0 & 25.4 & 6.4 & 0.26 & 8 & 23.7 & 47.9 & 24.2 & 0.79 \\
\hline 9 & 26.8 & 31.0 & 4.2 & 0.65 & 9 & 31.3 & 45.6 & 14.3 & 0.75 \\
\hline Mean & 27.5 & 38.5 & 11.0 & 0.40 & Mean & 29.9 & 51.4 & 21.4 & 0.65 \\
\hline SD & 3.9 & 7.0 & 4.4 & 0.11 & $\mathrm{SD}$ & 8.7 & 14.2 & 8.0 & 0.14 \\
\hline
\end{tabular}

${ }^{*}{ }_{\tau} \dot{\mathrm{V}}_{\mathrm{CO}_{2}}$ and $\tau \dot{\mathrm{V}}_{\mathrm{O}_{2}}$ were calculated by fitting the gas-exchange data to a first order exponential function starting at the onset of exercise. $\Delta \tau$ is the difference between $\tau \dot{\mathrm{V}}_{\mathrm{O}_{2}}$ and $\tau \dot{\mathrm{V}}_{\mathrm{CO}_{2}}$.

$\dagger \Delta \dot{\mathrm{V}}_{\mathrm{CO}_{2}}$ is the rest to exercise increase in $\dot{\mathrm{V}}_{\mathrm{CO}_{2}}$. 


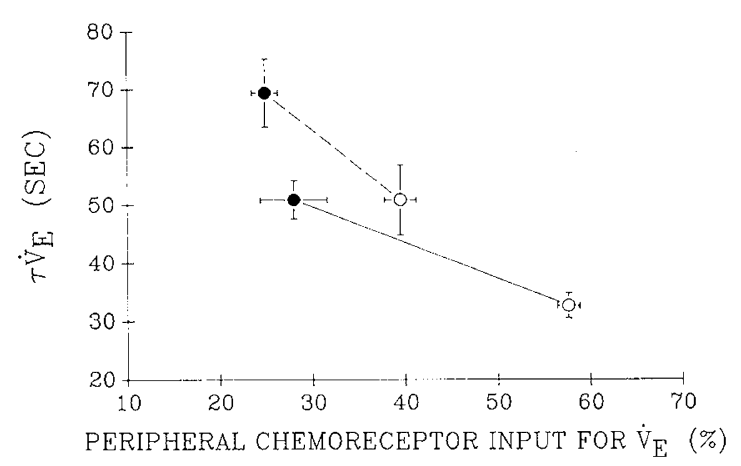

Fig. 5. $\tau \dot{\mathrm{V}}_{\mathrm{E}}$ as a function of peripheral chemoreceptor input for ventilation in children (solid line) and adults (broken line) during airbreathing (solid circle) and hypoxic-gas-breathing (open circle) (error bars indicate SEM). Peripheral chemoreceptor tone is shown on the $x$ axis as percentage of decrease in ventilation after the hyperoxic switch (6), and $\tau \dot{\mathrm{V}}_{\mathrm{E}}$ is shown on the $y$ axis in s. While breathing air, children had significantly shorter $\tau \dot{V}_{E}$ than adults despite there being no significant differences in the peripheral chemoreceptor tone. $\tau \dot{V}_{E}$ became significantly shorter in both children and adults under hypoxic conditions; however, was no difference in the magnitude of the change in the two groups. The peripheral chemoreceptor contribution to $\dot{V}_{E}$ was much greater in children compared to adults.

found reduced phase 1 ventilatory responses as a result of hypoxia in both the adults and children (Fig. 3). Acutely, reduction in the $\mathrm{Fi}_{\mathrm{O}_{2}}$ is known to result in an increased cardiac output, heart rate, and stroke vol (19), and, as noted, we observed increases in heart rate at rest and during exercise in the adults and children. Similar to the studies done during supine exercise (18), the magnitude of the stroke vol increase in the first $20 \mathrm{~s}$ of exercise may have been reduced in our subjects during hypoxia, and this could account for the reduced phase 1 ventilatory responses. Moreover, the finding that the relative change in phase 1 ventilation due to hypoxia was the same in the children (hypoxic phase $1 \dot{\mathrm{V}}_{\mathrm{E}}, 72 \pm 13 \%$ of the normoxic value) as in adults (hypoxic phase $1 \dot{\mathrm{V}}_{\mathrm{E}}, 78 \pm 14 \%$ ) is indirect evidence that the cardiac output effects of hypoxia were similar in adults and children.

It may be hypothesized that the circulation time (i.e. venous $\mathrm{vol} /$ cardiac output) can influence the phase 2 gas exchange and ventilatory kinetics at the onset of exercise. In fact, pulmonary circulation time appears to be only slightly shorter in children compared to adults. [Chalovpecky et al. (20) found pulmonary circulation time to be $4 \mathrm{~s}$ in 6 -y-old children and $6 \mathrm{~s}$ in 20 -y-old adults, using radiocirculographic methods.] If the circulation time had a functional effect on gas exchange kinetics at the onset of exercise, then we would have expected that both $\tau \dot{\mathrm{V}}_{\mathrm{O}_{2}}$ and $\tau \dot{\mathrm{V}}_{\mathrm{CO}_{2}}$ become longer with increasing age or body size. But, as demonstrated previously (21) and again in the present report, the $\dot{\mathrm{V}}_{\mathrm{O}_{2}}$ kinetics in children could not be distinguished from adults (Fig. 6). Therefore, it is unlikely that the different circulation times per se can explain the growth-related differences in $\tau \dot{\mathrm{V}}_{\mathrm{E}}$ and $\tau \dot{\mathrm{V}}_{\mathrm{CO}_{2}}$ we observed.

As noted, the relationship between peripheral chemoreceptor tone and ventilatory responses at the onset of exercise was different between children and adults both under room air- and hypoxic-breathing conditions. This suggested to us the possibility of a growth-related structural difference in the transport of $\mathrm{CO}_{2}$ from its production in the cells, to the respiratory centers and, ultimately, to the atmosphere. One likely mechanism was the relative size of $\mathrm{CO}_{2}$ stores in the body. Ward et al. (22) showed that volitional hyperventilation before exercise, which depleted $\mathrm{CO}_{2}$ stores, considerably slowed $\dot{\mathrm{V}}_{\mathrm{E}}$ and $\dot{\mathrm{V}}_{\mathrm{CO}_{2}}$ kinetics in normal subjects. Moreover, Poage et al. (23) have recently reported that $\dot{\mathrm{V}}_{\mathrm{E}}$ and $\dot{\mathrm{V}}_{\mathrm{CO}_{2}}$ kinetics at the onset of exercise in obese children were significantly slower as compared to normal controls, which

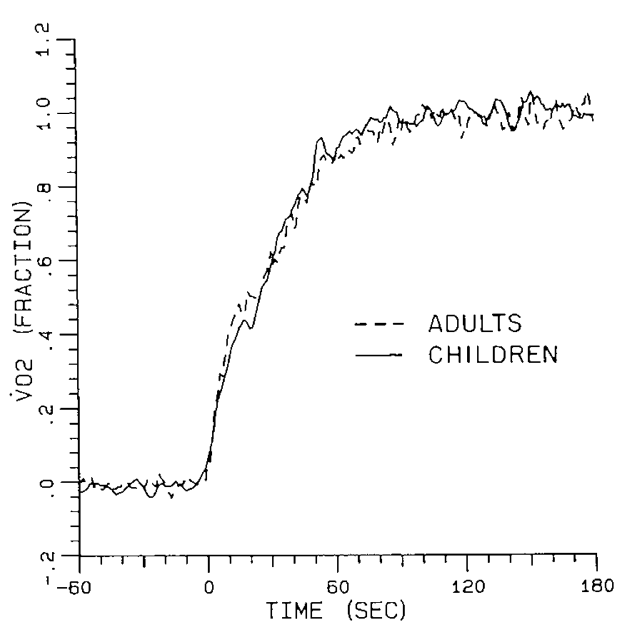

Fig. 6. Group mean responses of $\dot{\mathrm{V}}_{\mathrm{O}_{2}}$ to exercise during air-breathing in children and adults. Time 0 represents onset of exercise. $\dot{\mathrm{V}}_{\mathrm{O}_{2}}$ responses were normalized in the two groups and presented as the fractional change from rest $(0)$ to steady-state exercise (1.0). There was no difference in the response kinetics in the two groups.

may be due to the larger $\mathrm{CO}_{2}$ storage capacity in the obese children.

We found in children that the relative increase in tissue $\mathrm{CO}_{2}$ stores during exercise was smaller by $49 \%$ compared to adults. As less $\mathrm{CO}_{2}$ is stored at the onset of exercise, there may be a more rapid arrival of metabolically produced $\mathrm{CO}_{2}$ to the respiratory centers and lungs. This will result in a faster ventilatory response to exercise consistent with our findings. The putative difference in the relative $\mathrm{CO}_{2}$ storage capacity in children and adults may be related to factors such as differences in body composition, differences in $\mathrm{Hb}$ concentration (and thus vascular $\mathrm{CO}_{2}$ stores) or, perhaps, to a more fundamental difference of the tissue $\mathrm{CO}_{2}$ dissociation curve in children compared to adults.

In summary, we found that the coupling between peripheral chemoreceptor tone and ventilatory responses at the onset of exercise is not the same in children compared to adults. Under normoxic conditions, differences in the relative size of $\mathrm{CO}_{2}$ storage may explain the faster $\dot{\mathrm{V}}_{\mathrm{E}}$ and $\dot{\mathrm{V}}_{\mathrm{CO}_{2}}$ kinetics with exercise in children compared to adults, even though there was no significant difference in PCT. But an explanation for our finding that the increased PCT induced by hypoxia in children did not result in a proportional change in $\tau \mathrm{V}_{\mathrm{E}}$ and $\tau \dot{\mathrm{V}}_{\mathrm{CO}_{2}}$ is not readily apparent. We speculate that other aspects of ventilatory control mature during growth in children such that, as compared to adults, the ventilatory response at the onset of exercise is smaller for a given hypoxic stimulus.

\section{REFERENCES}

1. Griffiths TL, Henson LC, Whipp BJ 1986 Influence of inspired oxygen concentration on the dynamics of the exercise hyperpnoea in man. $J$ Physiol (Lond) 380:387-403

2. Rigatto H, Brady JB, Chir B, Verduzco R 1975 Chemoreceptor reflexes in preterm infants: $I$ : the effect of gestational age and postnatal age on ventilatory response to $100 \%$ and $15 \%$ oxygen. Pediatrics 55:604-613

3. Wasserman K, Whipp BJ, Koyal SN, Cleary MG 1975 Effect of carotid body resection on ventilatory and acid-base control during exercise. $J$ Appl Physiol 39:354-358

4. Dejours P, Labrousse Y, Raynaud J, Teillac A 1957 Stimulus oxygène chemoreflex de la ventilation à basse altitude $(50 \mathrm{~m})$ chez l'homme: I: au repos. J Physiol (Paris) 49:115-120

5. Dejours P 1963 Control of respiration by arterial chemoreceptors. Ann NY Acad Sci 109:682-695

6. Springer C, Cooper DM, Wasserman K 1988 Evidence that maturation of the peripheral chemoreceptors is not complete in childhood. Respir Physio $74: 55-64$

7. Wasserman K, Whipp BJ Casaburi R 1986 Respiratory control during exercise. In: Cherniack NS Widdicome JG (eds) Handbook of Physiology, vol 2. American Physiological Society, Bethesda, MD, pp 595--619

8. Cooper DM, Kaplan MR, Baumgarten L, Weiler-Ravel D, Whipp BJ, Wasser- 
man K 1987 Coupling ventilation and $\mathrm{CO}_{2}$ production during exercise in children. Pediatr Res 21:568-572

9. Wasserman K, Whipp BJ, Castanga J 1974 Cardiodynamic hyperpnea: hyperpnea secondary to cardiac output increase. J Appl Physiol 36:457-464

10. Whipp BJ, Davis JA, Torres F, Wasserman K 1981 A test to determine parameters of aerobic function during exercise. J Appl Physiol 50:217-221

11. Beaver WL, Lamarra N, Wasserman K 1981 Breath by breath measurement of true alveolar gas exchange. J Appl Physiol 51:166l-1675

12. Wasserman K, Whipp BJ, Koyal SN, Beaver WL 1973 Anaerobic threshold and respiratory gas exchange during exercise. J Appl Physiol 35:236-243

13. Cooper DM, Weiler-Ravel D, Whipp BJ, Wasserman K 1984 Aerobic param eters of exercise as a function of body size during growth in children. $J$ Appl Physiol 56:628-634

14. Lamarra N 1982 Ventilatory control, cardiac output, and gas exchange dynamics during exercise transitions in man. PhD thesis, University of California at Los Angeles, Los Angeles, CA

15. Whipp BJ, Ward SA, Lamarra N, Davis JA, Wasserman K 1982 Parameters of ventilatory and gas exchange dynamics during exercise. $\mathbf{J}$ Appl Physiol
52:1506-1513

16. Hughson RL, Inman MD 1985 Gas exchange analysis of immediate $\mathrm{CO}_{2}$ storage at onset of exercise. Respir Physiol 59:265-278

17. Yano $\mathrm{T} 1986 \mathrm{Immediate} \mathrm{CO}_{2}$ storage capacity at the onset of exercise. Japan J Physiol 36:1241-1252

18. Weiler-Ravell D, Cooper DM, Whipp BJ, Wasserman K 1983 Control of breathing at the start of exercise as influenced by posture. J Appl Physiol $55: 1460-1466$

19. Grover RF, Weil JV, Reeves JT 1986 Cardiovascular adaptation to exercise at high altitude. Exerc Sport Sci Rev 14:269-302

20. Chaoupecky V, Hruba M, Samanek M 1975 Pulmonary circulation time in healthy children and adolescents. Cesk Pediatr 30:478-481

21. Cooper DM, Berry C, Lamarra N, Wasserman K 1985 Kinetics of oxygen uptake and heart rate at onset of exercise. J Appl Physiol 59:211-217

22. Ward SA, Whipp BJ, Koyal SN, Wasserman K 1983 Influence of body $\mathrm{CO}_{2}$ stores on ventilatory dynamics during exercise. J Appl Physiol 55:742-749

23. Poage J, McCann ER, Cooper DM 1987 Ventilatory response to exercise in obese children. Am Rev Respir Dis 137:A23 (abstr) 